|| ISSN(online): 2589-8698 || ISSN(print): 2589-868X || International Journal of Medical and Biomedical Studies

Available Online at www.ijmbs.info

PubMed (National Library of Medicine ID: 101738825)

Index Copernicus Value 2017: 40.03

\title{
DYSPHAGIA LUSORIA: A LATE ONSET PRESENTATION
}

\section{Dr. Ajith Kumar $\mathrm{MG}^{1}$, Dr. Roja VR}

${ }^{1}$ MBBS DMRD DNB FAMS., Consultant Radiologist, Malabar Hospitals and Urology Centre; \& Baby Memorial Hospital Calicut, Kerala

${ }^{2}$ Research Scientist (M)-I, ICMR-NTF HI Project, ENT and HNS Department, AIIMS Raipur

Article Info: Received 10 February 2019; Accepted 08 March. 2019

Cite this article as: Kumar MG, Dr. A., \& VR, Dr. R. (2019). DYSPHAGIA LUSORIA: A LATE ONSET PRESENTATION. International Journal of Medical and Biomedical Studies, 3(3).

DOI: https://doi.org/10.32553/ijmbs.v3i3.143

Address for Correspondence: Dr. Ajith Kumar MG, MBBS DMRD DNB FAMS., Consultant Radiologist, Malabar Hospitals and Urology Centre; \& Baby Memorial Hospital Calicut, Kerala

Conflict of interest: No conflict of interest.

\section{Abstract}

Dysphagia lusoria is the term used to describe dysphagia following vascular compression of oesophagus. Diagnosis can be made by barium and contrast enhanced CT SCAN. The present case describes a late on set dysphagia secondary to aberrant right subclavian artery.

Key words: Dysphagia, Dysphagia lusoria, endoscopy, ARSA, CT Scan, ENT, GI and ECG

\section{Introduction:}

Dysphagia Lusoria is an abnormal condition characterised by difficulty in swallowing (dysphagia) caused by a vascular compression of the right subclavian artery to oesophagus also known as Bayford-Autenrieth dysphagia. First case was discovered in 1761 by David Bay Ford (1). Describing a longstanding case of dysphagia leading to emaciation and eventual death of a 62-year-old female on autopsy patient found to have aberrant right subclavian artery. Majority of the case ARSA runs posterior to cause oesophageal compression and dysphagia ${ }^{(3)}$. This is the most common anomaly of the aortic arch, representing $17 \%$ of this malformation group and the incidence of aberrant right subclavian artery ranges from $0.2 \%$ to $2.5 \%$. The symptoms are usually silent and mostly it as an incidental finding at necropsy ${ }^{(5)}$. In the present case describes a late onset dysphagia due to aberrant right subclavian artery.

\section{Case Report:}

\section{History:}

An 83-year-old male subject presented to the ENT department with difficulty in swallowing (dysphagia) to solids, foreign body sensation in throat and food sticking sensation. There was no significant medical history as well as family history reported. No weight loss was reported. Past medical history and physical examination was unremarkable.

\section{Methods:}

Current case was reported in ENT Department and after a detail case history was obtained along with physical examination. Then the case was referred for Routine blood examination, chest x-ray, barium swallow examination, CT Scan and ECG.

\section{Result:}

Routine blood examination, chest x-ray and ECG all were well within normal range. Then the 
patient subjected for barium swallow examination which reveals normally appearing pharynx and upper oesophagus. Posterior esophagal impression detected in the upper oesophagus. A contrast CT demonstrates an aberrant right subclavian originating from the lower third of aortic arch and it is traversing posterior to oesophagus.

As an empirical way of treatment proton pump inhibitors and domperidone were introduced getting certain occasional symptomatic relief.

Since the patient age and other comorbidities forced us to propel away from any other vascular reversion procedures. Patient was advised follow certain lifestyle and nutritional modifications.

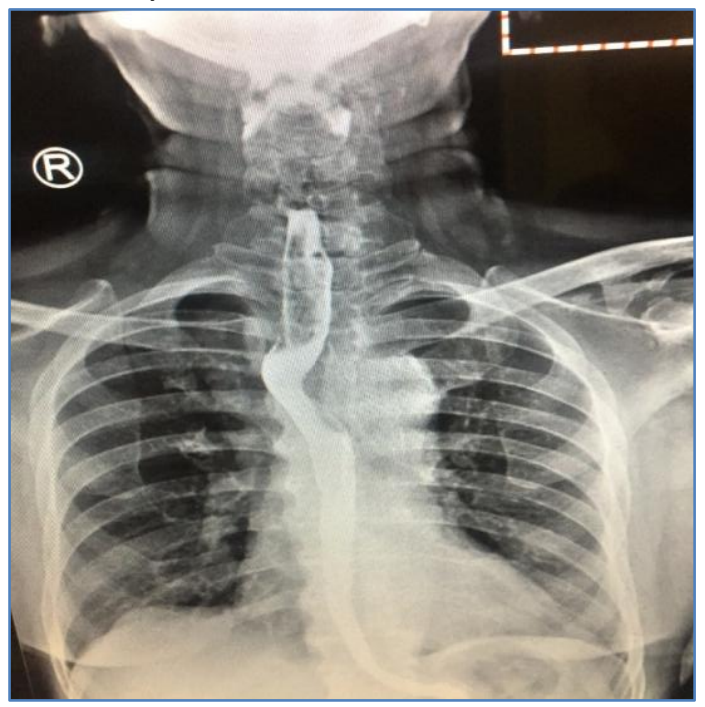

Figure 1: Barium swallow AP View shows impression in upper posterior wall of oesophagus by aberrant right subclavian artery

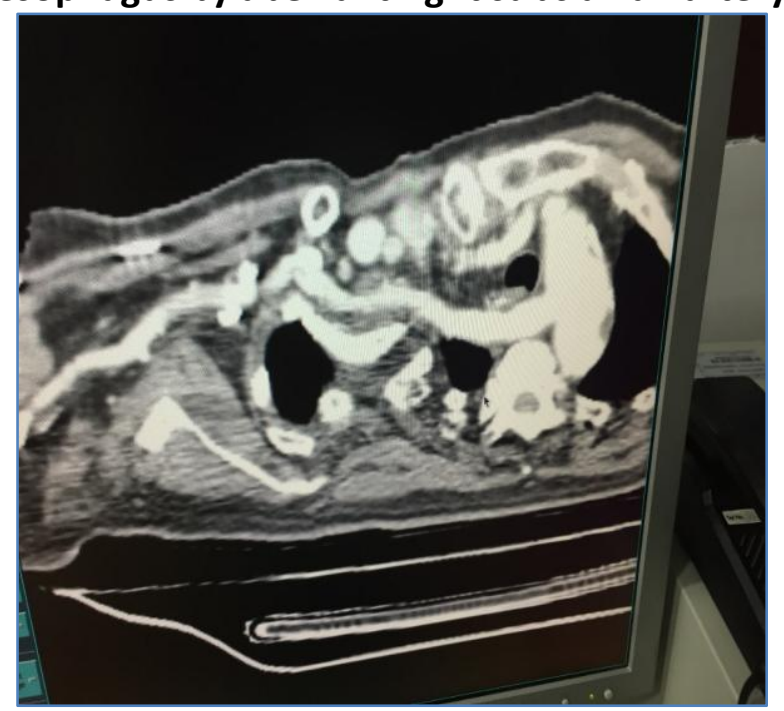

Figure 2:

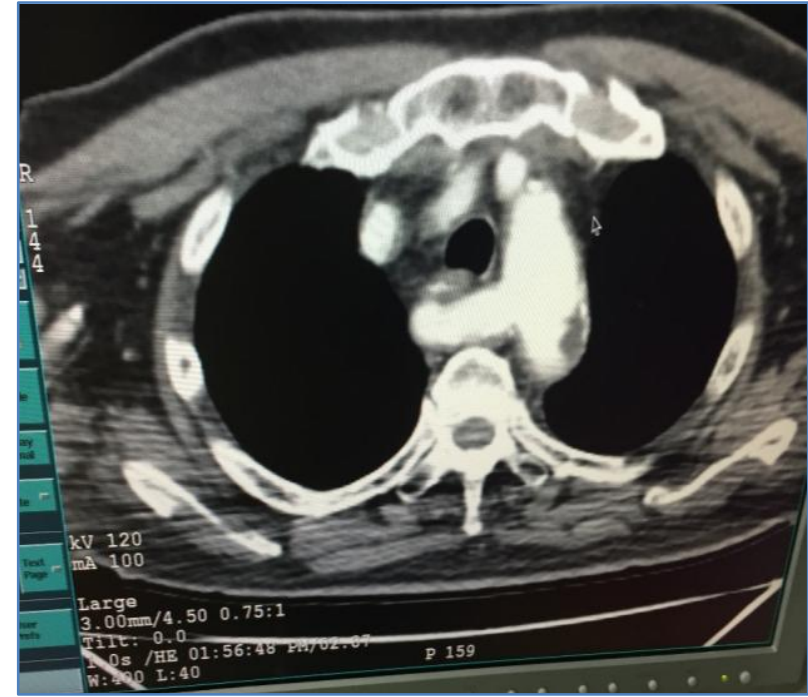

Figure 3: figure $2^{\text {nd }}$ and $3^{\text {rd }}$ shows CECT Chest, ARSA originating from right aortic arch, leaving an impression behind the posterior oesophageal wall

\section{Discussion:}

ARSA is a common variant of embryonic aortic arch involution within the general population ${ }^{(3)}$. This occurs as a consequence of a persistent 7th intersegmental artery with involution of 4th vascular arch with the right dorsal aorta (4, 5).Majority of the cases aberrant artery traverses posterior to the oesophagus but in a small proportion it may run anterior to the oesophagus, as in the original description of the syndrome by BAYFORD ${ }^{(1)}$. Certain times Kommerell's diverticulum accompanies the ARSA (3). In rare eventualities kommerell's diverticulum may become aneurismal with subsequent oesophageal compression and dysphagia $(6,7)$.

Haesemeyer etal conducted a study in 7174 trauma patients along with CT scan and found 29 ARSA cases ${ }^{(8)}$. Another study conducted by Abhaichand et al in 3730 patients underwent for trans radial coronary angiography and found 14 cases with ARSA ${ }^{(9)}$. Fockens etal done endoscopic ultrasound for 1629 subjects and fond 6 cases of ARSA ${ }^{(10)}$. Kelly ${ }^{(11)}$ found a single case out of 223 patients subjected for upper GI endoscopy for dysphagia.

Aberrant subclavian arteries are present on routine endoscopy as a pulsatile posterior indentation in the upper oesophagus, however 
endoscopic diagnosis is rare. Majority of cases are from right subclavian originating from left sided aortic arch, similar abnormality is also possible from a left aberrant subclavian extending from right sided aortic arch, however which is much rarer ${ }^{(13,14)}$. This anomaly develops when the right dorsal artery remains patent and either the left arch or left dorsal aorta regresses abnormally.

A complete vascular ring is formed when the left ductus arteriosus associated with ARSA, where left sided ductus arteriosus passing from left subclavian artery to the proximal left pulmonary artery. Majority presented with dysphagia for solid foods ${ }^{(3)}$. Sometimes it remains dormant and incidentally detected following investigations done for other conditions. Dynamic barium swallow studies and vascular reconstruction studies done by using modalities like CT and MRI help us to plan for vascular reversal surgeries if at all needed. Late onset symptoms can be attributed to dysmotility disorders of oesophagus, stiffening of the vessel due to atherosclerosis and aortic elongation with increased traction on the obstructing vessel and aneurysmal dilatations in the presence of Kommerell's diverticulum ${ }^{(2)}$.

Management depends on the severity of the dysphagia and the ability of the patients to maintain a proper weight and nutrition. Almost half of the (50\%) of the cases can be managed by dietary modifications and rephase the chewing habits. Severe symptomatic patients not responding to interventional dietary and swallowing strategies may warrant surgical treatment. Gross (17) first reported surgical management of this condition describing the division and ligation of aberrant right subclavian artery, in a 4-month-old child Via thoracotomy. Lichter ${ }^{(18)}$ described surgery on an adult patient left postero- lateral thoracotomy.

Our case presented with late onset dysphagia due to ARSA managed with dietary and swallowing modifications, surgical line of management not needed.

\section{Funding:}

There is no funding.

\section{Consent:}

Written informed consent was obtained from the patient for publication of this case report and accompanying images.

\section{Author contribution:}

Every author has contributed equally in this work.

\section{Footnotes:}

In this case report we present an interesting case of a right subclavian retroesophageal artery that we have discovered in our institution. The data was collected from our records and from the literature.

\section{References:}

1. Asherson N. David Bayford. His syndrome and sign of dysphagia lusoria. Ann R Coll Surg Engl. 1979;61:63-67. [PMC free article] [PubMed]

2. Janssen $M$, Baggen $M G$, Veen $H F$, Smout $A J$, Bekkers JA, Jonkman JG, Ouwendijk RJ. Dysphagia lusoria: clinical aspects, manometric findings, diagnosis, and therapy. Am J Gastroenterol. 2000;95:14111416. [PubMed]

3. Levitt B, Richter JE. Dysphagia lusoria: a comprehensive review. Dis Esophagus. 2007; 20:455-460.[PubMed]

4. Taylor M, Harris KA, Casson AG, DeRose G, Jamieson WG. Dysphagia lusoria: extrathoracic surgical management. Can J Surg. 1996; 39:48-52. [PMC free article] [PubMed]

5. Dandelooy J, Coveliers JP, Van Schil PE, Anguille S. Dysphagia lusoria. CMAJ. 2009;181:498.[PMC free article] [PubMed]

6. Triantopoulou C, Ioannidis I, Komitopoulos $\mathrm{N}$, Papailiou J. Aneurysm of aberrant right subclavian artery causing Dysphagia lusoria in an elderly patient. AJR Am J Roentgenol. 2005;184:1030-1032. [PubMed] 
7. Singh S, Grewal PD, Symons J, Ahmed A, Khosla S, Arora R. Adult-onset dysphagia lusoria secondary to a dissecting aberrant right subclavian artery associated with type $B$ acute aortic dissection. Can J Cardiol. 2008;24:63-65. [PMC free article] [PubMed]

8. Haesemeyer SW, Gavant ML. Imaging of acute traumatic aortic tear in patients with an aberrant right subclavian artery. AJR Am J Roentgenol. 1999;172:117-120. [PubMed]

9. Abhaichand RK, Louvard Y, Gobeil JF, Loubeyre C, Lefèvre T, Morice MC. The problem of arteria lusoria in right transradial coronary angiography and angioplasty. Catheter Cardiovasc Interv. 2001;54:196201. [PubMed]

10. Fockens P, Kisman K, Tytgat GNJ. Endosonographic imaging of an aberrant right subclavian (lusorian) artery. Gastrointestinal Endosc. 1996;43:419.

11. Kelly MD. Endoscopy and the aberrant right subclavian artery. Am Surg. 2007;73:12591261.[PubMed]

12. Molz G, Burri B. Aberrant subclavian artery (arteria lusoria): sex differences in the prevalence of various forms of the malformation. Evaluation of 1378 observations. Virchows Arch A Pathol Anat Histol. 1978;380:303-315. [PubMed]
13. McNally PR, Rak KM. Dysphagia lusoria caused by persistent right aortic arch with aberrant left subclavian artery and diverticulum of Kommerell. Dig Dis Sci. 1992; 37:144-149. [PubMed]

14. Panduranga $P, A l$-Delamie $T$, Ratnam $L, A l-$ Mukhaini M, Zachariah S. Repair of Kommerell's diverticulum with aberrant left subclavian artery in an elderly patient with right aortic arch and dysphagia lusoria.J Card Surg. 2011;26:637-640. [PubMed]

15. Grishaw EK, Ott DJ, Frederick MG, Gelfand DW, Chen MY. Functional abnormalities of the esophagus: a prospective analysis of radiographic findings relative to age and symptoms. AJR Am J Roentgenol. 1996;167: 719-723. [PubMed]

16. Tack J, Vantrappen G. The aging oesophagus. Gut. 1997;41:422-424. [PMC free article] [PubMed]

17. Gross RE. Surgical treatment for dysphagia lusoria. Ann Surg. 1946;124:532-534. [PMC free article][PubMed]

18. Lichter I. The treatment of dysphagia lusoria in the adult. Br J Surg. 1963;50:793-796. [PubMed]

19. Morris $C D$, Kanter KR, Miller Jl. Late-onset dysphagia lusoria. Ann Thorac Surg. 2001;71: 710-712.[PubMed] 